\title{
Angela Kershaw, Forgotten Engagements. Women, Literature and the Left in $1930^{\mathrm{s}}$ France
}

\section{Emanuela Cavicchi}

\section{(2) OpenEdition}

1 Journals

\section{Edizione digitale}

URL: http://journals.openedition.org/studifrancesi/8359

DOI: 10.4000/studifrancesi.8359

ISSN: 2421-5856

\section{Editore}

Rosenberg \& Sellier

\section{Edizione cartacea}

Data di pubblicazione: 1 mai 2009

Paginazione: 206

ISSN: 0039-2944

Notizia bibliografica digitale

Emanuela Cavicchi, «Angela Kershaw, Forgotten Engagements. Women, Literature and the Left in $1930^{\text {s }}$ France», Studi Francesi [Online], 157 (LIII | I) | 2009, online dal 30 novembre 2015, consultato il 10 janvier 2021. URL: http://journals.openedition.org/studifrancesi/8359 ; DOI: https://doi.org/10.4000/ studifrancesi.8359

Questo documento è stato generato automaticamente il 10 janvier 2021.

\section{(c) 9 (i) $\Theta$}

Studi Francesi è distribuita con Licenza Creative Commons Attribuzione - Non commerciale - Non opere derivate 4.0 Internazionale. 


\title{
Angela Kershaw, Forgotten Engagements. Women, Literature and the Left in $1930^{\text {s }}$ France
}

\author{
Emanuela Cavicchi
}

\section{NOTIZIA}

ANGELA KERSHAW, Forgotten Engagements. Women, Literature and the Left in $1930^{\text {s }}$ France, Amsterdam-New York, Rodopi, 2007 («Faux titre», 291), pp. 306.

1 Il saggio prende in considerazione cinque scrittrici attive in Francia negli anni Trenta, che si sono dedicate all'impegno politico di sinistra tramite la loro vita e i loro scritti: Madeleine Pelletier, Simone Téry, Edith Thomas, Henriette Valet, Louise Weiss. Si tratta di autrici, come sottolinea Kershaw, che sono state dimenticate o ignorate dalla storia della letteratura tradizionale, e le cui opere si trovano attualmente fuori stampa. Questo studio si pone come obiettivi il recupero e la diffusione di una parte di Storia, e di storia letteraria, negletta e da sempre relegata ai margini, per restituire memoria e dignità di ricerca al contributo femminile nella formazione di un determinato contesto storico-culturale.

2 Il saggio cerca in particolar modo di definire il tipo di engagement letterario di queste autrici, che hanno operato una precisa scelta stilistica nel tentativo di unire, in alcune loro opere, la forma romanzesca a un contenuto politicizzato, secondo i canoni del roman à thèse. Angela Kershaw dimostra che le fictions prodotte dalle cinque scrittrici, pur ricalcando modelli maschili, arrivano a produrre almeno parzialmente delle variazioni originali - anche se non sempre esteticamente valide - proprio in conseguenza della specificità dell'esperienza femminile dell'impegno politicoletterario, che sarà necessariamente diversa da quella di un uomo, per il contesto storico e sociale in cui le opere sono state concepite. 
3 La studiosa parte infatti dalla considerazione che le autrici hanno scritto delle fictions politiche in Francia nel momento storico compreso tra le due guerre mondiali, durante il quale la nozione di littérature engagée è stata al centro del dibattito culturale. Sono gli anni in cui viene definito il ruolo dell'intellettuale rispetto al partito comunista, ai "diktat" di Mosca, alla lotta ai fascismi, e le cui scelte estetiche vengono giudicate in relazione alla causa rivoluzionaria. Nel prendere in considerazione i romanzi di queste scrittrici, Kershaw analizza contemporaneamente, in maniera documentata e approfondita, il difficile contesto in cui le opere sono nate: non si può infatti dimenticare che la cultura politica dell'epoca escludeva formalmente le donne dalla partecipazione attiva, negando loro il diritto di voto; inoltre, anche all'interno del partito comunista e dei giornali legati alla sinistra, il loro ruolo era volutamente circoscritto.

4 Le cinque autrici studiate simboleggiano una doppia contraddizione: esse non solo scrivevano, ma scrivevano di politica, stravolgendo così ogni cliché dell'epoca secondo cui le donne scrittrici tradivano un fallimento personale del ruolo in famiglia a loro destinato, e in questo échec non potevano che produrre una mediocre letteratura intrisa di sentimentalismo.

5 Contro questi pregiudizi, l'analisi di Kershaw si sofferma sulle rappresentazioni dell'impegno femminile nelle protagoniste delle fictions considerate, che fanno emergere, tra le maglie talvolta rigide della letteratura orientata ideologicamente, delle costanti proprie della condizione femminile: il corpo della donna dal punto di vista della sessualità e della maternità, l'utopia dell'uguaglianza dei generi o la rivendicazione di una differenza positiva, la lotta per il diritto al voto, la denuncia dello svilimento del ruolo della donna alla sola funzione riproduttiva.

6 Queste scrittrici e le loro opere contribuiscono in maniera significativa, secondo Kershaw, a rileggere e a comprendere meglio le sfumature e le variazioni della letteratura politica prodotta in Francia negli anni Trenta: «It is crucial to situate this experience within the bigger picture, and to reconsider the bigger picture in the light of women's experiences» (p. 6). 